\title{
Supported bifunctional thioureas as recoverable and reusable catalysts for enantioselective nitro-Michael reactions
}

\author{
José M. Andrés ${ }^{*}$, Miriam Ceballos, Alicia Maestro, Isabel Sanz and Rafael Pedrosa*
}

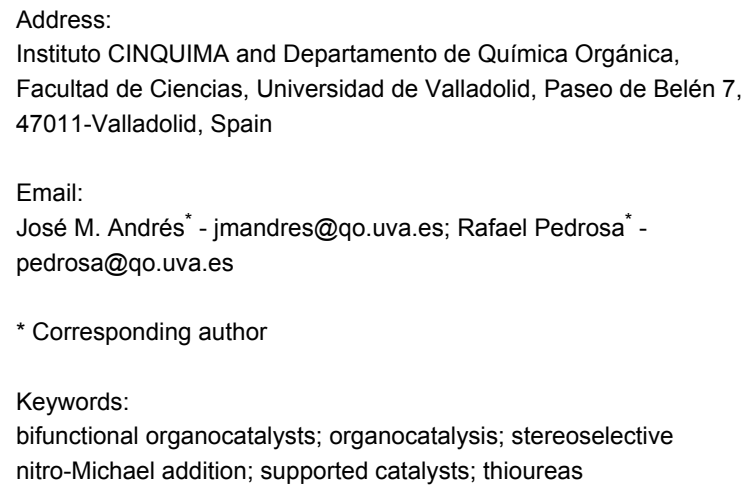

\begin{abstract}
The catalytic activity of different supported bifunctional thioureas on sulfonylpolystyrene resins has been studied in the nitroMichael addition of different nucleophiles to trans- $\beta$-nitrostyrene derivatives. The activity of the catalysts depends on the length of the tether linking the chiral thiourea to the polymer. The best results were obtained with the thiourea derived from (L)-valine and 1,6-hexanediamine. The catalysts can be used in only $2 \mathrm{~mol} \%$ loading, and reused for at least four cycles in neat conditions. The ball milling promoted additions also worked very well.
\end{abstract}

\section{Introduction}

The use of chiral bifunctional thioureas that allow the simultaneous activation of a electrophile, by hydrogen bonding, and a nucleophile, by deprotonation, plays a major role in the stereoselective formation of $\mathrm{C}-\mathrm{C}$ bonds in different transformations [1-5]. In these processes one of the major problems is related to the recovering of the catalysts. The support of the small molecules on different materials has been proposed as a solution, including their use in continuous flow processes [6-9]. The most popular supports include nanoparticles [10-12], inorganic solids $[13,14]$, and different polystyrene derivatives [15-20].

Bifunctional thioureas were first supported on PEG [21], and later on different materials such as poly(methylhydrosiloxane)
[16], polystyrene [18-22], and magnetic nanoparticles [12]. Cinchona-derived thioureas have been also prepared by co-polymerization of polyfunctionalized thiols with olefins [23].

Our interest in the search for novel bifunctional thioureas as organocatalysts [24-27] lead us to consider the preparation of different polymeric materials decorated with chiral bifunctional thioureas looking for a greener process [28], easier recovering and recyclability of the catalyst, and solvent-free reaction conditions. Along these lines, we have recently reported the bottom-up synthesis of polymeric thioureas [29], and the anchorage of (L)-valine-derived thiourea I [30] onto 
sulfonylpolystyrene resin leading to catalysts II-V (Figure 1), which differ in the length of the diamine linker or in the substitution pattern of the nitrogen in the sulfonamide. These materials, and the related unsupported thiourea VI, have been previously tested as excellent organocatalysts in the stereoselective aza-Henry reaction [31]. Now we describe the results obtained in different stereoselective nitro-Michael additions promoted by these materials.

\section{Results and Discussion}

The ability of the supported catalysts (II-V) to promote the stereoselective nitro-Michael reaction was first tested in the reaction of trans-nitrostyrene (1a) with diethyl malonate (2a), leading to the enantioenriched addition product $4 \mathbf{a a}$ with a single stereocenter. In order to the creation of two tertiaryquaternary contiguous stereocenters (5aa) we also used ethyl 2-oxocyclopentanecarboxylate (3a) as nucleophile in neat conditions and in different solvents. For comparative purposes, the same reactions were studied in the presence of unsupported catalysts $\mathbf{I}$ and VI, and the results are summarized in Scheme 1 and Table 1.

Initially, the reactions were carried out in neat conditions at $\mathrm{rt}$ with twofold excess of nucleophile and $10 \mathrm{~mol} \%$ of catalysts (entries 1-4 and 9-11 in Table 1). As a general trend, the reac- tions were faster, and much more stereoselective for ketoester 3a than for diethyl malonate $\mathbf{2 a}$, and that the difference was specially remarkable when supported ethylenediamine-derived thioureas II and III were used as catalysts (compare entries 2 and 3 versus 9 and 10 in Table 1). It is noteworthy that the results obtained in the reaction catalyzed by supported thiourea IV were better than those observed in the addition catalyzed by the parent thiourea I (compare Table 1, entries 1 and 4).

The catalyst loading was decreased to $5 \mathrm{~mol} \%$ for supported hexanediamine-derived catalyst $\mathbf{I V}$, observing that the level of stereoselectivity was maintained for both reactions, although at expenses of slight increasing the reaction time (compare Table 1, entries 4 versus 5, and 11 versus 12). In these conditions, supported catalyst $\mathbf{V}$, which differs from IV in the substitution pattern of the sulfonamide, was the best catalyst for the addition of both 2a and 3a to nitrostyrene, yielding products 4aa and 5aa, respectively, in much better yield maintaining the stereoselectivity in shorter reaction time (compare entries 5 versus 6 and 12 versus 13 in Table 1). An increase in both the yield and the enantioselectivity for the reaction of $\mathbf{1 a}$ with $\mathbf{2 a}$ (Table 1, entries 6 and 7), but no differences in the reaction of 1a with 3a (Table 1, entries 13 and 14) were observed when the unsupported thiourea VI, homologous to $\mathbf{V}$, was used as organocatalyst.<smiles>CC(C)[C@H](CN(C)C)NC(=S)Nc1cc(C(F)(F)F)cc(C(F)(F)F)c1</smiles>

I

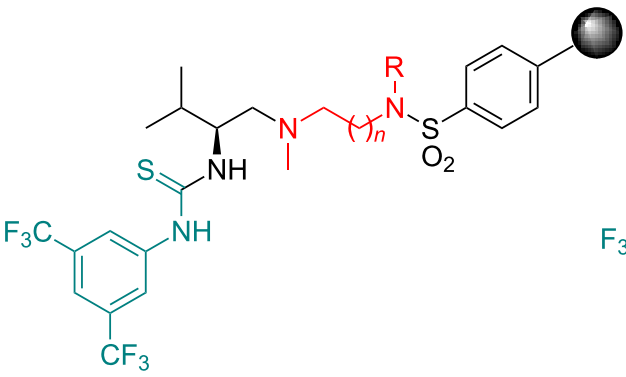

II: $n=1 ; \mathrm{R}=\mathrm{H}$, III: $n=1 ; \mathrm{R}=\mathrm{Me}$

IV: $n=5 ; \mathrm{R}=\mathrm{H}, \mathbf{V}: n=5 ; \mathrm{R}=\mathrm{Me}$<smiles>[R]NC(=[W])CN(C)C[C@H](NC(=S)Nc1cc(C(F)(F)F)cc(C(F)(F)F)c1)C(C)C</smiles>

VI: $n=5 ; \mathrm{R}=\mathrm{Me}$

Figure 1: Parent and supported bifunctional thioureas used in this work.

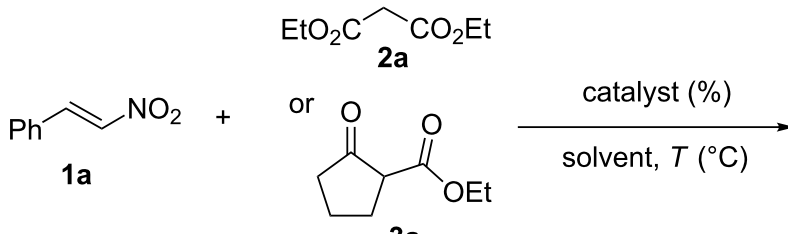

3a

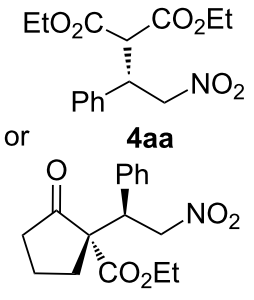

5 aa 
Table 1: Screening of catalysts and optimization of the reaction conditions for the additions of diethyl malonate and ethyl 2-oxocyclopentanecarboxylate to $\beta$-nitrostyrene.

\begin{tabular}{|c|c|c|c|c|c|c|c|}
\hline Entry ${ }^{a}$ & Catal. (mol \%) & Solvent & $T\left({ }^{\circ} \mathrm{C}\right)$ & $t(\mathrm{~h})$ & Product yield ${ }^{b}(\%)$ & $d r^{C}$ & $e r^{d}$ \\
\hline 1 & I (10) & neat & $\mathrm{rt}$ & 24 & 4aa (80) & - & $92: 8$ \\
\hline 2 & II (10) & neat & $\mathrm{rt}$ & 120 & 4aa $(77)^{\mathrm{e}}$ & - & $78: 22$ \\
\hline 3 & III (10) & neat & $\mathrm{rt}$ & 120 & 4aa $(63)^{f}$ & - & $85: 15$ \\
\hline 4 & IV (10) & neat & $\mathrm{rt}$ & 16 & 4aa (92) & - & $91: 9$ \\
\hline 5 & IV (5) & neat & $\mathrm{rt}$ & 24 & 4aa $(80)$ & - & $90: 10$ \\
\hline 6 & $\mathbf{V}(5)$ & neat & $\mathrm{rt}$ & 16 & 4aa (92) & - & $89: 11$ \\
\hline 7 & VI (5) & neat & $\mathrm{rt}$ & 16 & 4aa (100) & - & $94: 6$ \\
\hline 8 & I (5) & neat & $\mathrm{rt}$ & 1 & 5aa (95) & $95: 5$ & $95: 5$ \\
\hline 9 & II (10) & neat & $\mathrm{rt}$ & 4 & 5aa (100) & $89: 11$ & $90: 10$ \\
\hline 10 & III /10) & neat & $\mathrm{rt}$ & 8 & 5aa $(90)$ & $87: 13$ & $92: 8$ \\
\hline 11 & IV (10) & neat & $\mathrm{rt}$ & 4 & 5aa (100) & $88: 12$ & $95: 5$ \\
\hline 12 & IV (5) & neat & $\mathrm{rt}$ & 7 & 5 aа (100) & 88:12 & $95: 5$ \\
\hline 13 & $\mathbf{V}(5)$ & neat & $\mathrm{rt}$ & 0.5 & 5aa (98) & $89: 11$ & $95: 5$ \\
\hline 14 & VI (5) & neat & $\mathrm{rt}$ & 2 & $5 a a(100)$ & $89: 11$ & $95: 5$ \\
\hline 15 & $\mathbf{V}(2)$ & neat & $\mathrm{rt}$ & 1 & $5 a a(93)$ & $89: 11$ & $95: 5$ \\
\hline 16 & $\mathbf{V}(2)$ & neat & 0 & 24 & $5 a a(97)$ & $90: 10$ & $94: 6$ \\
\hline $17^{9}$ & $\mathbf{V}(2)$ & neat & $\mathrm{rt}$ & 8 & 5aa (86) & $88: 12$ & $94: 6$ \\
\hline $18^{h}$ & $\mathbf{V}(2)$ & neat & $\mathrm{rt}$ & 2.5 & 5aa (83) & $88: 12$ & $94: 6$ \\
\hline 19 & $\mathbf{V}(2)$ & $\mathrm{CH}_{2} \mathrm{Cl}_{2}$ & $\mathrm{rt}$ & 1 & 5aa (74) & $90: 10$ & $93: 7$ \\
\hline 20 & $\mathbf{V}(2)$ & PhMe & $\mathrm{rt}$ & 5 & 5aa (66) & 89:11 & $94: 6$ \\
\hline 21 & $\mathbf{V}(2)$ & THF & $\mathrm{rt}$ & 1.5 & 5aa (55) & $89: 11$ & $94: 6$ \\
\hline 22 & $\mathbf{V}(2)$ & $\mathrm{MeCN}$ & $\mathrm{rt}$ & 1.5 & 5аa (79) & 89:11 & $95: 5$ \\
\hline 23 & $\mathbf{V}(2)$ & $\mathrm{MeCN}$ & 0 & 8 & 5 aа (82) & $88: 12$ & $95: 5$ \\
\hline $24^{g}$ & $\mathbf{V}(2)$ & $\mathrm{MeCN}$ & $\mathrm{rt}$ & 8 & $5 a a(86)$ & $89: 11$ & $92: 8$ \\
\hline
\end{tabular}

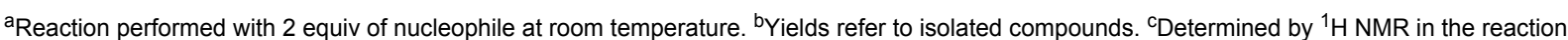
mixture. ${ }^{d}$ Determined by chiral HPLC. ${ }^{e} 13 \%$ of unreacted nitrostyrene was recovered. ${ }^{\mathrm{f}} 15 \%$ of unreacted nitrostyrene was recovered. ${ }^{\mathrm{g}} \mathrm{Reaction}$ per-

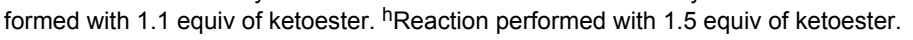

Taking the supported thiourea $\mathbf{V}$ as the catalyst of choice, the effects of the catalyst loading, the temperature, the ratio of nucleophile, and the use of different solvents were studied for the reaction of $\mathbf{1 a}$ and $\mathbf{3 a}$. Fortunately, the reduction of the amount of catalyst to $2 \mathrm{~mol} \%$ did not influence the stereoselectivity, and only slightly decreased the yield to $93 \%$ (compare Table 1, entries 13 and 15). The reaction also proceeded at $0{ }^{\circ} \mathrm{C}$, leading to the addition product $\mathbf{5} \mathbf{a a}$ in $97 \%$ and very good stereoselectivity, but in those conditions the reaction time increased to $24 \mathrm{~h}$ (Table 1, entry 16).

The reduction of the amount of the nucleophile to 1.1 equivalents (Table 1, entry 17) or 1.5 equivalents (Table 1, entry 18) had only a moderate effect on the yield of the reaction time, increasing it to $8 \mathrm{~h}$ and $2,5 \mathrm{~h}$, respectively. The yield dropped to $55-74 \%$, without change in the stereoselectivity, when the reaction was carried out in less polar solvents such as DCM, toluene, or THF (Table 1, entries 19-21), although both the yield and diastereo- and enantioselectivity were maintained when acetonitrile, a more polar solvent, was used (Table 1, entries 22-24).

We next consider the reaction of some 4-substituted nitrostyrenes (1)-d) with diethyl malonate (2a), and the addition of a range of $\beta$-functionalized nucleophiles $\mathbf{2 b}-\mathbf{g}$ to $\mathbf{1 a}$ promoted by supported catalysts IV (5 mol \%) and V (2 mol \%), respectively (Scheme 2 and Table 2). The results obtained in the reactions of 4-chloro- (1b) and 4-fluoronitrostyrene (1c) were very similar than those obtained in the reaction with $\beta$-nitrostyrene (1a), maintaining the yield and the enantioselectivity, although 1c reacted slowly within $48 \mathrm{~h}$ (compare entries 1 and 2 in Table 2 versus entry 5 in Table 1), but the less reactive 4-methoxy derivative $1 \mathbf{d}$ only yielded the addition product in moderate $52 \%$ yield after $72 \mathrm{~h}$ of reaction (entry 3 in Table 2 ).

The reaction of different nucleophiles $(\mathbf{2 a}-\mathbf{g})$ with 1 a catalyzed by IV ( $5 \mathrm{~mol} \%)$ also worked well in terms of enantioselectivity, maintaining the er near constant around or higher than 90:10, 


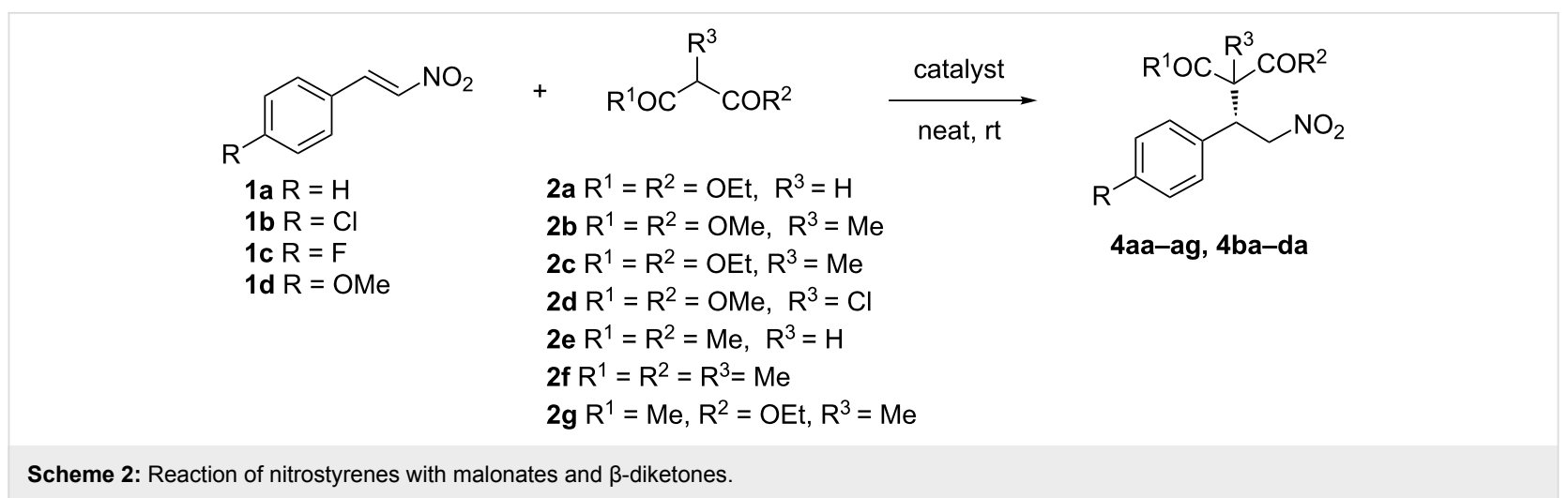

Table 2: Addition of malonates and $\beta$-diketones to nitrostyrenes catalyzed by IV and $\mathbf{V}$.

\begin{tabular}{|c|c|c|c|c|c|c|c|}
\hline Entrya & Reagents & Catal. (mol \%) & $t(\mathrm{~h})$ & Product yield ${ }^{\mathrm{b}}(\%)$ & $\mathrm{dr}^{\mathrm{c}}$ & $e r^{d}$ & Config. \\
\hline 1 & $1 b / 2 a$ & IV (5) & 6 & 4ba (76) & - & $83: 17$ & $(S)$ \\
\hline 2 & $1 c / 2 a$ & IV (5) & 48 & 4ca (72) & - & $86: 14$ & $(S)$ \\
\hline 3 & $1 d / 2 a$ & IV (5) & 72 & 4da (52) & - & $89: 11$ & $(S)$ \\
\hline 4 & $1 \mathrm{a} / 2 \mathrm{~b}$ & IV (5) & 36 & $4 a b(64)$ & - & $92: 8$ & $(R)$ \\
\hline 5 & $1 \mathrm{a} / 2 \mathrm{~d}$ & IV (5) & 48 & 4ad (74) & - & $92: 8$ & $(S)$ \\
\hline 6 & $1 \mathrm{a} / 2 \mathrm{e}$ & IV (5) & 5 & 4ae (88) & - & $89: 11$ & $(S)$ \\
\hline 7 & $1 a / 2 f$ & IV (5) & 6 & 4af $(70)$ & - & $93: 7$ & $(R)$ \\
\hline 8 & $1 \mathrm{a} / 2 \mathrm{~g}$ & IV (5) & 7 & 4ag (99) & $75: 25$ & $92: 8$ & $(2 R, 3 R)$ \\
\hline 9 & $1 a / 2 b$ & $\mathbf{V}(2)$ & 2 & $4 a b(46)$ & - & $91: 9$ & $(R)$ \\
\hline 10 & $1 \mathrm{a} / 2 \mathrm{c}$ & $\mathbf{V}(2)$ & 8 & $4 a c(47)$ & - & $91: 9$ & $(R)$ \\
\hline 11 & $1 \mathrm{a} / 2 \mathrm{~d}$ & $\mathbf{V}(2)$ & 2 & 4ad (43) & - & $91: 9$ & $(S)$ \\
\hline 12 & $1 \mathrm{a} / 2 \mathrm{e}$ & $\mathbf{V}(5)$ & 2 & 4ae (87) & - & $92: 8$ & $(S)$ \\
\hline 13 & $1 \mathrm{a} / 2 \mathrm{f}$ & $\mathbf{V}(2)$ & 3 & 4af (65) & - & $93: 7$ & $(R)$ \\
\hline 14 & $1 \mathrm{a} / 2 \mathrm{~g}$ & $\mathbf{V}(2)$ & 6 & 4ag (81) & $74: 26$ & $94: 6$ & $(2 R, 3 R)$ \\
\hline
\end{tabular}

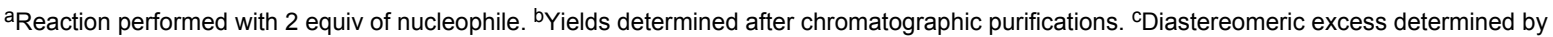
${ }^{1} \mathrm{H}$ NMR of the crude reaction mixture. ${ }^{\mathrm{d}}$ Enantiomeric ratio determined by chiral HPLC analysis.

although the stereoselectivity for the reaction leading to $\mathbf{4 a g}$, with two contiguous tertiary-quaternary stereocenters was only moderate ( $\mathrm{dr} 75: 25$, entry 8 in Table 2 ). The main difference in those additions was related with the reaction time, because the less reactive malonates $(\mathbf{2 b}$ and $\mathbf{2 d}$ ) reacted slower than the acetylacetone (2e and $\mathbf{2 f}$ ) or ethyl acetoacetate (2g) derivatives.

Similar results were obtained when the reaction was run in the presence of only 2 mol \% of catalyst $\mathbf{V}$ (entries 9-14 in Table 2). The level of stereoselectivity was maintained, including the diastereoselectivity for the reaction of $\mathbf{1 a}$ with $\mathbf{2 g}$ ( $\mathrm{dr}$ 74:26), but the yields for the reactions with 2-substituted malonates (2b-d) were only moderate (entries 9-11 in Table 2).

Next, we extend the study to the reaction of different $\beta$-functionalized cycloalkanones (3a-c), 2-acetylcyclopentanone (3d), and 2 -acetyl- $\gamma$-lactone (3e) with nitrostyrene derivatives $\mathbf{1 a - d}$
(Scheme 3 and Table 3). The electronic nature of the nitroolefins only affects the yield and the reaction time, being longer as the donating effect of the substituent increases, but maintaining good diastereoselectivity and excellent enantioselectivity for all reactions (entries 2-4, Table 3).

With respect to the nucleophile, it is noteworthy that there seems to be a correlation: With growing size of the cycloalkanone an increase of the reaction time and a decrease of the yield can be observed. Cycloheptanone 3c, and specially cyclohexanone $\mathbf{3 b}$ reacted much more slowly than cyclopentanone derivative 3a (Table 3, entries 5, 6, and 8), although the reaction time could be reduced from $96 \mathrm{~h}$ to $10 \mathrm{~h}$ in the reaction of 1a with $\mathbf{3 b}$ by increasing the catalyst loading from $2 \mathrm{~mol} \%$ to $5 \mathrm{~mol} \%$ (Table 3, entry 7). It is also noteworthy that 2 -acetyl- $\gamma$ lactone (3e) reacted very well with 1a, leading to 5ae in excellent yield and enantioselectivity, but only moderate diastereoselectivity (dr 70:30, Table 3, entry 10). 


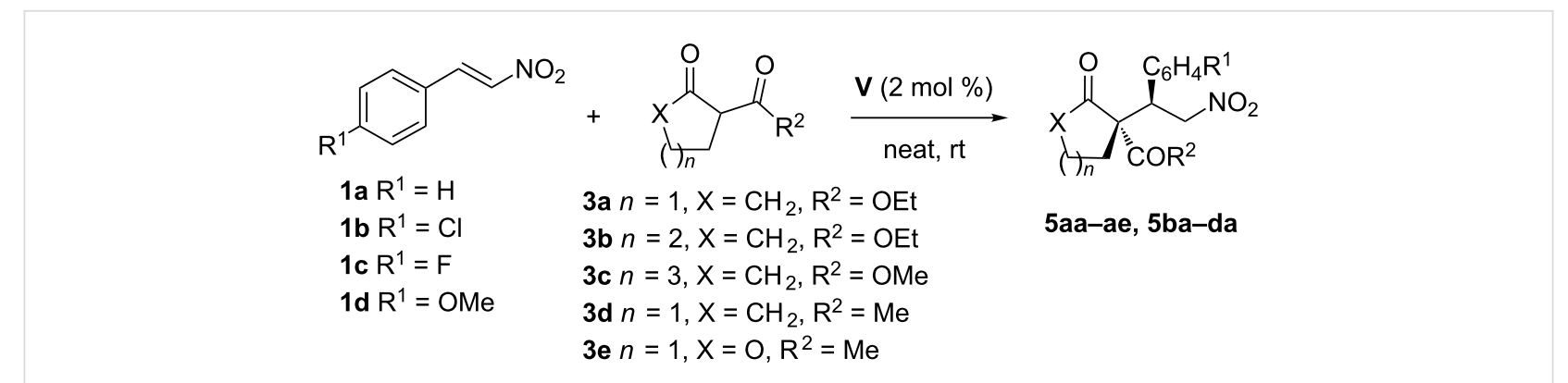

Scheme 3: Reaction of nitrostyrenes with $\beta$-keto esters and $\beta$-dicarbonyl compounds.

\begin{tabular}{|c|c|c|c|c|c|c|c|}
\hline Entry $^{a}$ & Reagents & Catal. (mol \%) & $t(\mathrm{~h})$ & Product Yield ${ }^{\mathrm{b}}(\%)$ & $\mathrm{dr}^{\mathrm{C}}$ & $e r^{d}$ & Config. \\
\hline 1 & $1 a / 3 a$ & $\mathbf{V}(5)$ & 0.5 & 5aa (98) & $89: 11$ & $95: 5$ & $(S, R)$ \\
\hline 2 & $1 b / 3 a$ & $\mathbf{V}(2)$ & 1 & 5 ba (84) & $90: 10$ & $94: 6$ & $(S, R)$ \\
\hline 3 & $1 c / 3 a$ & $\mathbf{V}(2)$ & 5 & $5 c a(76)$ & $89: 11$ & $93: 7$ & $(S, R)$ \\
\hline 4 & $1 d / 3 a$ & $\mathbf{V}(2)$ & 9 & $5 \mathrm{da}(74)$ & $89: 11$ & $95: 5$ & $(S, R)$ \\
\hline 5 & $1 a / 3 a$ & $\mathbf{V}(2)$ & 1 & 5aa (93) & $89: 11$ & $95: 5$ & $(S, R)$ \\
\hline 6 & $1 a / 3 b$ & $\mathbf{V}(2)$ & 96 & $5 a b(63)$ & $88: 12$ & $96: 4$ & $(S, R)$ \\
\hline 7 & $1 a / 3 b$ & $\mathbf{V}(5)$ & 10 & $5 a b(62)$ & $88: 12$ & $96: 4$ & $(S, R)$ \\
\hline 8 & $1 a / 3 c$ & $\mathbf{V}(2)$ & 24 & 5 ac (73) & $82: 18$ & $96: 4$ & $(S, R)$ \\
\hline 9 & $1 \mathrm{a} / 3 \mathrm{~d}$ & $\mathbf{V}(2)$ & 2 & 5ad (92) & 83:17 & $93: 7$ & $(R, R)$ \\
\hline 10 & $1 \mathrm{a} / 3 \mathrm{e}$ & $\mathbf{V}(2)$ & 1 & 5ae (89) & $70: 30$ & $92: 8$ & $(R, R)$ \\
\hline $11^{\mathrm{e}}$ & $1 \mathbf{a} / 3 a$ & $\mathbf{V}(5)$ & 1 & 5 aa $(81)$ & $88: 12$ & $94: 6$ & $(S, R)$ \\
\hline $12^{f}$ & $1 a / 3 a$ & $\mathbf{V}(5)$ & 1 & 5aa (76) & $88: 12$ & $95: 5$ & $(S, R)$ \\
\hline $13^{9}$ & $1 a / 3 a$ & $\mathbf{V}(5)$ & 2 & 5 aa (82) & $88: 12$ & $94: 6$ & $(S, R)$ \\
\hline
\end{tabular}

${ }^{a}$ Reaction performed with 2 equiv of nucleophile. ${ }^{b}$ Yields determined after chromatographic purifications. ${ }^{\mathrm{c} D i a s t e r e o m e r i c ~ e x c e s s ~ d e t e r m i n e d ~ b y ~}$

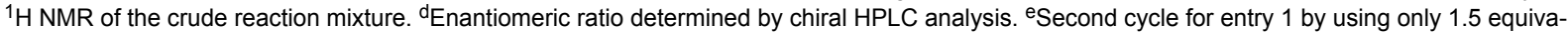
lents of nucleophile. ${ }^{\mathrm{f}}$ Third cycle for entry 1 by using only 1.5 equivalents of nucleophile. 9Fourth cycle for entry 1 by using only 1.5 equivalents of nucleophile.

To test the recyclability of catalyst $\mathbf{V}$ we choose the reaction of 1a with 3a in neat conditions and $5 \mathrm{~mol} \%$ of catalyst as model. Once the reaction had finished (TLC), the catalyst was recovered by filtration, and after washing with methanol and drying to constant weight, the catalyst was used in the next cycle (entries 1 and 11-13 in Table 3). Fortunately, catalyst $\mathbf{V}$ can be reused for at least four cycles yielding 5aa in high yields (76-82\%), and maintaining both the diastereo- and enantioselectivity.

Finally, $\alpha$-nitrocyclohexanone (6a) and ethyl $\alpha$-nitropropionate (6b) were included in the screening process in order to compare the results obtained with more acidic nucleophiles with those obtained with $\beta$-dicarbonyl derivatives. The reactions were carried out under different conditions by varying the solvent, the temperature and using unsupported thioureas $\mathbf{I}$ and $\mathbf{V I}$, and $\mathbf{V}$ as an example of a supported one (Scheme 4). The most significant difference between the reactions of nitroketone and nitroester refers to the stereoselectivity in both processes. The addition of nitroketone was totally diastereoselective and highly enantioselective (entries 1-12 in Table 4), whereas both the diastero- and enantioselectivities were moderate for the addition of nitroester (Table 4, entries 13-15). Additionally, supported catalyst $\mathbf{V}$ was able to promote more enantioselective transformations than unsupported catalyst I (compare Table 4, entry 13 versus 15 ). The decrease of the temperature slows down the reaction, increasing the reaction time from $1 \mathrm{~h}$ to $6 \mathrm{~h}$ for the reaction of $\mathbf{1 a}$ with $\mathbf{6 b}$, catalyzed by I (Table 4, entries 13 and 14), and from $24 \mathrm{~h}$ to $48 \mathrm{~h}$ for the addition of $\mathbf{6 a}$ to $\mathbf{1 a}$ catalyzed for VI (Table 4, entries 7 and 8), but maintaining the diastereoselectivity and slightly increasing the enantioselectivity. The donor character of the substituent in the nitrostyrene derivative plays an important role in the process, increasing the reaction time, and decreasing the yield (compare Table 4, entries 5, 9, and 11).

The recent interest in alternative activation modes [32] for promoting $\mathrm{C}-\mathrm{C}$ bond formations, led us to consider the catalyt- 


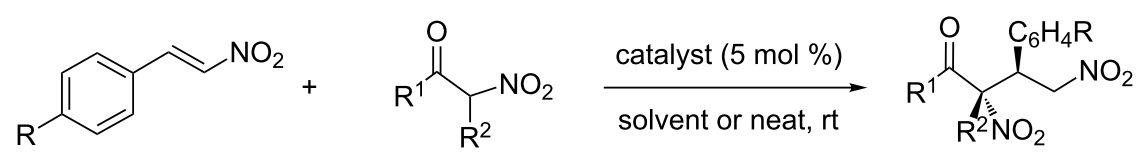

$$
\begin{aligned}
& \text { 1a } \mathrm{R}=\mathrm{H} \quad 6 \mathbf{a} \mathrm{R}^{1}, \mathrm{R}^{2}=\left(\mathrm{CH}_{2}\right)_{4} \\
& \text { 1b } R=C l \quad 6 b R^{1}=O E t, R^{2}=M e
\end{aligned}
$$

7aa-da, 7ab

Scheme 4: Reaction of nitrostyrenes with a-nitrocyclohexanone and ethyl a-nitropropionate.

\begin{tabular}{|c|c|c|c|c|c|c|c|}
\hline Entry $^{a}$ & Reagents & Catal. (mol \%) & $t(\mathrm{~h})$ & Solvent & Product yield ${ }^{b}(\%)$ & $\mathrm{dr}^{\mathrm{C}}$ & $e r^{d}$ \\
\hline 1 & $1 \mathrm{a} / 6 \mathrm{a}$ & I (5) & 3 & $\mathrm{DCM}$ & $7 \mathbf{a a}(62)$ & $>98:<2$ & $84: 16$ \\
\hline 2 & $1 \mathrm{a} / 6 \mathrm{a}$ & I (5) & 1.5 & neat & $7 \mathbf{a a}(65)$ & $>98:<2$ & $90 / 10$ \\
\hline $3^{e}$ & $1 a / 6 a$ & I (5) & 1 & neat & 7 aa (70) & $>98:<2$ & $90: 10$ \\
\hline 4 & $1 a / 6 a$ & $\mathbf{V}(5)$ & 48 & $\mathrm{DCM}$ & $7 a a(60)$ & $>98:<2$ & $90: 10$ \\
\hline 5 & $1 a / 6 a$ & $\mathbf{V}(5)$ & 12 & $\mathrm{MeCN}$ & 7aa (77) & $>98:<2$ & $91: 9$ \\
\hline $6^{e}$ & $1 \mathrm{a} / 6 \mathrm{a}$ & $\mathbf{V}(5)$ & 12 & neat & 7aa (85) & $>98:<2$ & $94: 6$ \\
\hline 7 & $1 a / 6 a$ & VI (5) & 24 & $\mathrm{DCM}$ & 7aa (64) & $>98:<2$ & $85: 15$ \\
\hline $8^{f}$ & $1 a / 6 a$ & VI (5) & 48 & $\mathrm{DCM}$ & 7 aa (52) & $>98:<2$ & $92: 8$ \\
\hline 9 & $1 b / 6 a$ & $\mathbf{V}(5)$ & 8 & $\mathrm{MeCN}$ & 7 ba $(91)$ & $>98:<2$ & $91: 9$ \\
\hline $10^{e}$ & $1 b / 6 a$ & $\mathbf{V}(5)$ & 48 & neat & 7 ba $(48)^{9}$ & $>98:<2$ & $90: 10$ \\
\hline 11 & $1 d / 6 a$ & $\mathbf{V}(5)$ & 24 & $\mathrm{MeCN}$ & $7 \mathrm{da}(73)$ & $>98:<2$ & $89: 11$ \\
\hline $12^{\mathrm{e}}$ & $1 d / 6 a$ & $\mathbf{V}(5)$ & 360 & neat & $7 \mathrm{da}(50)^{\mathrm{h}}$ & $>98:<2$ & $87: 13$ \\
\hline 13 & $1 \mathrm{a} / 6 \mathrm{~b}$ & $I(5)$ & 1 & neat & $7 \mathrm{ab}(75)$ & $74: 26$ & $69: 31$ \\
\hline $14^{f}$ & $1 \mathrm{a} / 6 \mathrm{~b}$ & I (5) & 6 & neat & $7 \mathrm{ab}(77)$ & $75: 25$ & $72: 28$ \\
\hline 15 & $1 \mathrm{a} / 6 \mathrm{~b}$ & $\mathbf{V}(5)$ & 5 & neat & $7 \mathrm{ab}(90)$ & $76: 24$ & $74: 26$ \\
\hline
\end{tabular}

Table 4: Reactions of nitrostyrenes with a-nitrocyclohexanone and ethyl a-nitropropionate.

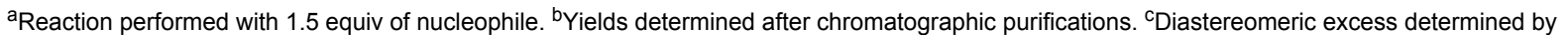
${ }^{1} \mathrm{H}$ NMR of the crude reaction mixture $(>98:<2$ means that a single diastereomer was detected). dEnantiomeric ratio determined by chiral HPLC analysis. ${ }^{e}$ Ball mill conditions. ${ }^{f}$ The reaction was carried out at $-20{ }^{\circ} \mathrm{C}$. $937 \%$ of 2 -nitrocyclohexanone was recovered unreacted. ${ }^{\mathrm{h}} 30 \%$ of 2 -nitrocyclohexanone was recovered unreacted.

ic addition of $\alpha$-nitrocyclohexanone (6a) to nitrostyrene derivatives $\mathbf{1 a}, \mathbf{1 b}$, and $\mathbf{1 d}$ under ball milling conditions [33]. We chose these reactions for comparative purposes because they have been previously reported [34]. Although the experimental conditions have not been optimized, we observed that both the unsupported (I) and supported (V) catalysts worked very well in the reaction of $1 \mathbf{a}$ with $\mathbf{6 a}$ yielding the addition product $7 \mathbf{a a}$ in excellent yields and stereoselectivity (entries 3 and 6 in Table 4). On the contrary, the reactions of $\mathbf{6 a}$ with $\mathbf{1 b}$ and $\mathbf{1 d}$ are very slow and $37 \%$ and $30 \%$ of the nucleophile were recovered unchanged after $48 \mathrm{~h}$ and $360 \mathrm{~h}$ of reaction, respectively, although maintaining the stereoselectivity (Table 4, entries 10 and 12). The improvement of that process is under study.

\section{Conclusion}

In summary, supported bifunctional thioureas on sulfonylpolystyrene are able to promote highly stereoselective nitro-Michael reactions with different nucleophiles. The activity of the cata- lysts varies with the length of the tether between the polymer and the thiourea framework, and the best results were obtained by using catalysts $\mathbf{I V}$ and $\mathbf{V}$, derived from 1,6-hexanediamine. The reactions work well by using only $2 \mathrm{~mol} \%$ of catalyst loading in neat conditions, and the catalysts can easily be recovered and reused for four cycles. The results obtained with the described catalysts are similar to those previously reported by using bottom-up synthesized materials prepared by co-polymerization of monomeric thioureas as organocatalysts [29]. Catalyst $\mathbf{V}$ has been also used in the addition of $\alpha$-nitrocyclohexanone (6a) to $\beta$-nitrostyrene (1a) under solvent-free conditions in a ball mill providing the addition product $7 \mathbf{a a}$ in excellent yield, total diastereoselectivity, and very good enantioselectitvity.

\section{Experimental}

\section{General remarks}

${ }^{13} \mathrm{C}$ NMR (126 MHz) and ${ }^{1} \mathrm{H}$ NMR (500 MHz) spectra were recorded in $\mathrm{CDCl}_{3}$ as the solvent. Chemical shifts for carbons are 
reported in ppm from TMS and are referenced to the carbon resonance of the solvent. Chemical shifts for protons are reported in ppm from TMS with the residual $\mathrm{CHCl}_{3}$ resonance as internal reference. Data are reported as follows: chemical shift, multiplicity $(\mathrm{s}=$ singlet, $\mathrm{d}=$ doublet, $\mathrm{t}=$ triplet, $\mathrm{q}=$ quartet, $\mathrm{m}=$ multiplet, br $=$ broad), coupling constants in Hertz, and integration.

Flash chromatography was carried out using silica gel (230-240 mesh). TLC analysis was performed on glass-backed plates coated with silica gel 60 and an $\mathrm{F}_{254}$ indicator, and visualized by either UV irradiation or by staining with phosphomolybdic acid solution. Specific rotations were measured on a digital polarimeter using a $5 \mathrm{~mL}$ cell with a $1 \mathrm{dm}$ path length, and a sodium lamp, and the concentration is given in $\mathrm{g}$ per $100 \mathrm{~mL}$. Chiral HPLC analysis was performed by using Daicel Chiralcel OD or Chiralpak AD-H, analytical columns $(250 \times 4.6 \mathrm{~mm})$ by using mixture of $n$-hexane/isopropanol as eluent. UV detection was monitored at 220 or at $254 \mathrm{~nm}$. ESI mass spectra were obtained on an Agilent 5973 inert GC/MS system. Commercially available organic and inorganic compounds were used without further purification. Solvents were dried and stored over microwave-activated $4 \AA$ molecular sieves. Supported thioureas II-V and unsupported thioureas I and VI were prepared according to reported procedures [30,31]. Racemic reference samples were prepared by using DABCO ( $5 \mathrm{~mol} \%$ ) following the same procedure as described below.

General procedure for the nitro-Michael reaction using homogeneous catalysts (I and VI). The reactions were carried out as previously described [29]. To a mixture of nitrostyrene $(0.3 \mathrm{mmol})$ and catalyst $(0.015 \mathrm{mmol}, 0.05$ equiv $)$, the $1,3-$ dicarbonyl compound ( $0.6 \mathrm{mmol}, 2$ equiv) was added and the reaction mixture was stirred at $\mathrm{rt}$ in a Wheaton vial until consumption of the starting material (monitoring by TLC). The reaction mixture was purified by column chromatography to afford the Michael product. The anti- and syn-isomers of the Michael products were not separated by column chromatography. The diastereomeric ratio was determined by ${ }^{1} \mathrm{H}$ NMR spectroscopy of the purified product.

General procedure for the nitro-Michael reaction using inmobilized catalysts (II, III, IV and V) [29]. To a mixture of $\beta$-nitrostyrene $(0.3 \mathrm{mmol})$ and catalyst $(0.015 \mathrm{mmol}$, 0.05 equiv), 1,3-dicarbonyl compound ( $0.6 \mathrm{mmol}, 2$ equiv) was added and the reaction mixture was stirred at $\mathrm{rt}$ in a Wheaton vial until consumption of the starting material (monitored by TLC). The catalyst was filtered off and washed with $\mathrm{MeOH}$ $(3 \times 1 \mathrm{~mL})$. The solvent was removed under reduced pressure, and the residue was purified by column chromatography. The anti- and syn-isomers of the Michael products were not separat- ed by column chromatography. The diastereomeric ratio was determined by ${ }^{1} \mathrm{H}$ NMR spectroscopy of the purified product.

\section{Recyclability of the supported thiourea catalysts in nitro-}

Michael reaction. The supported catalysts were recovered from the reaction mixtures by filtration, thoroughly washed with methanol, dried and reused in the next cycle.

\section{General procedure for the Michael addition of 2-nitrocyclohexanone to $\beta$-nitrostyrene using immobilized catalyst $\mathbf{V} \mathbf{I}$}

Method A, in organic solvent: The reactions were carried out as previously described [29]. To a stirred solution of 2-nitrocyclohexanone (43 mg, $0.3 \mathrm{mmol}$ ) and nitroalkene $(0.45 \mathrm{mmol}$, 1.5 equiv) in an adequate solvent $(0.4 \mathrm{~mL})$, catalyst VI $(15 \mathrm{mg}$, $0.015 \mathrm{mmol}, 0.05$ equiv) was added and the reaction mixture was stirred at room temperature in a Wheaton vial until the reaction was finished (TLC). The catalyst was filtered off and washed with DCM $(3 \times 1 \mathrm{~mL})$. The solvent was removed under reduced pressure, the crude mixture subjected to flash chromatography to afford the Michael adduct. The diastereomeric ratio was determined by ${ }^{1} \mathrm{H}$ NMR spectroscopy of the purified product. The enantiomeric excess was determined by chiral-phase HPLC analysis using mixtures of hexane/ isopropanol as eluent.

Method B, under ball-milling conditions: Catalyst VI (15 mg, $0.015 \mathrm{mmol}, 0.05$ equiv), 2-nitrocyclohexanone (43 mg, $0.3 \mathrm{mmol})$ and nitroalkene $(0.45 \mathrm{mmol}, 1.5$ equiv) were transferred to a clean, dry ball milling vessel (cylinder of $5 \mathrm{~mL}$ ) loaded with two grinding balls with a $7 \mathrm{~mm}$ diameter. The vessel was placed in a Mixer Mill MM 200 and the mixture was milled at $5 \mathrm{~Hz}$ of vibrational frequency at room temperature until consumption of the starting material (monitored by TLC). The vessel and the balls were washed with $\mathrm{CH}_{2} \mathrm{Cl}_{2}$, the catalyst was filtered off and washed with $\mathrm{CH}_{2} \mathrm{Cl}_{2}$ and methanol. The resulting solution was concentrated in vacuo, and the product was purified by flash chromatography. The diastereomeric ratio was determined by ${ }^{1} \mathrm{H}$ NMR spectroscopy of the purified product. The enantiomeric excess was determined by chiral-phase HPLC analysis using mixtures of hexane/isopropanol as eluent.

\section{Supporting Information}

\section{Supporting Information File 1}

Physical and spectral data for all the compounds. Copies of ${ }^{1} \mathrm{H},{ }^{13} \mathrm{C}$ NMR spectra, and HPLC traces for all compounds synthesized.

[http://www.beilstein-journals.org/bjoc/content/ supplementary/1860-5397-12-61-S1.pdf] 


\section{Acknowledgements}

We acknowledge the financial support provided by the Spanish MINECO (Project CTQ2014-59870-P) and Junta de Castilla y León (Project VA064U13).

\section{References}

1. Takemoto, Y. Org. Biomol. Chem. 2005, 3, 4299-4306. doi:10.1039/b511216h

2. Taylor, M. S.; Jacobsen, E. N. Angew. Chem., Int. Ed. 2006, 45, 1520-1543. doi:10.1002/anie.200503132

3. Connon, S. J. Chem. Commun. 2008, 2499-2510. doi:10.1039/B719249E

4. Connon, S. J. Synlett 2009, 354-376. doi:10.1055/s-0028-1087557

5. Lu, L.-Q.; An, X.-L.; Chen, J.-R.; Xiao, W.-J. Synlett 2012, 490-508. doi:10.1055/s-0031-1290131

6. Ayats, C.; Henseler, A. H.; Pericàs, M. A. ChemSusChem 2012, 5, 320-325. doi:10.1002/cssc.201100570

7. Bortolini, O.; Caciolli, L.; Cavazzini, A.; Costa, V.; Greco, R.; Massi, A.; Pasti, L. Green Chem. 2012, 14, 992-1000. doi:10.1039/c2gc16673a

8. Rodríguez-Escrich, C.; Pericàs, M. A. Eur. J. Org. Chem. 2015, 1173-1188. doi:10.1002/ejoc.201403042

9. Kasaplar, P.; Ozkal, E.; Rodríguez-Escrich, C.; Pericàs, M. A. Green Chem. 2015, 17, 3122-3129. doi:10.1039/C5GC00496A

10. Gawande, M. B.; Branco, P. S.; Varma, R. S. Chem. Soc. Rev. 2013, 42, 3371-3393. doi:10.1039/c3cs35480f

11. Jiang, X.; Zhu, H.; Shi, X.; Zhong, Y.; Li, Y.; Wang, R. Adv. Synth. Catal. 2013, 355, 308-314. doi:10.1002/adsc.201201038

12. Gleeson, O.; Davies, G.-L.; Peschiulli, A.; Tekoriute, R.; Gun'ko, Y. K.; Connon, S. J. Org. Biomol. Chem. 2011, 9, 7929-7940. doi:10.1039/c1ob06110k

13. Puglisi, A.; Annunziata, R.; Benaglia, M.; Cozzi, F.; Gervasini, A.; Bertacche, V.; Sala, M. C. Adv. Synth. Catal. 2009, 351, 219-229. doi:10.1002/adsc.200800635

14. Yu, P.; He, J.; Guo, C. Chem. Commun. 2008, 2355-2357. doi:10.1039/b800640g

15. Gruttadauria, M.; Giacalone, F.; Noto, R. Chem. Soc. Rev. 2008, 37, 1666-1688. doi:10.1039/b800704g

16. Puglisi, A.; Benaglia, M.; Annunziata, R.; Siegel, J. S. ChemCatChem 2012, 4, 972-975. doi:10.1002/cctc.201200114

17. Fotaras, S.; Kokotos, C. G.; Kokotos, G. Org. Biomol. Chem. 2012, 10 , 5613-5619. doi:10.1039/c2ob25693b

18. Tuchman-Shukron, L.; Miller, S. J.; Portnoy, M. Chem. - Eur. J. 2012, 18, 2290-2296. doi:10.1002/chem.201102474

19. Li, J.; Yang, G.; Cui, Y. J. Appl. Polym. Sci. 2011, 121, 1506-1511. doi:10.1002/app.33676

20. Li, J.; Yang, G.; Qin, Y.; Yang, X.; Cui, Y. Tetrahedron: Asymmetry 2011, 22, 613-618. doi:10.1016/j.tetasy.2011.03.016

21. Miyabe, H.; Tuchida, S.; Yamauchi, M.; Takemoto, Y. Synthesis 2006, 3295-3300. doi:10.1055/s-2006-950196

22. Chuan, Y.; Chen, G.; Peng, Y. Tetrahedron Lett. 2009, 50, 3054-3058. doi:10.1016/j.tetlet.2009.04.011

23. Fredriksen, K. A.; Kristensen, T. E.; Hansen, T. Beilstein J. Org. Chem. 2012, 8, 1126-1133. doi:10.3762/bjoc.8.125

24. Manzano, R.; Andrés, J. M.; Muruzábal, M. D.; Pedrosa, R. Adv. Synth. Catal. 2010, 352, 3364-3372. doi:10.1002/adsc.201000612

25. Manzano, R.; Andrés, J. M.; Pedrosa, R. Synlett 2011, 2203-2205. doi:10.1055/s-0030-1261139
26. Manzano, R.; Andrés, J. M.; Álvarez, R.; Muruzábal, M. D.; Rodríguez de Lera, A.; Pedrosa, R. Chem. - Eur. J. 2011, 17, 5931-5938. doi:10.1002/chem.201100241

27. Manzano, R.; Andrés, J. M.; Muruzábal, M.-D.; Pedrosa, R. J. Org. Chem. 2010, 75, 5417-5420. doi:10.1021/jo100792r

28. Sheldon, R. A. Chem. Soc. Rev. 2012, 41, 1437-1451. doi:10.1039/C1CS15219J

29. Andrés, J. M.; de La Cruz, N.; Valle, M.; Pedrosa, R. ChemPlusChem 2016, 81, 86-92. doi:10.1002/cplu.201500476

30. Andrés, J. M.; Manzano, R.; Pedrosa, R. Chem. - Eur. J. 2008, 14, 5116-5119. doi:10.1002/chem.200800633

31. Pedrosa, R.; Andrés, J. M.; Ávila, D. P.; Ceballos, M.; Pindado, R. Green Chem. 2015, 17, 2217-2225. doi:10.1039/C4GC02474E

32. Baig, R. B. N.; Varma, R. S. Chem. Soc. Rev. 2012, 41, 1559-1584. doi:10.1039/C1CS15204A See for a recent review.

33. Stolle, A.; Szuppa, T.; Leonhardt, S. E. S.; Ondruschka, B. Chem. Soc. Rev. 2011, 40, 2317-2329. doi:10.1039/c0cs00195c

34. Jörres, M.; Mersmann, S.; Raabe, G.; Bolm, C. Green Chem. 2013, 15, 612-616. doi:10.1039/c2gc36906k

\section{License and Terms}

This is an Open Access article under the terms of the Creative Commons Attribution License (http://creativecommons.org/licenses/by/2.0), which permits unrestricted use, distribution, and reproduction in any medium, provided the original work is properly cited.

The license is subject to the Beilstein Journal of Organic Chemistry terms and conditions:

(http://www.beilstein-journals.org/bjoc)

The definitive version of this article is the electronic one which can be found at: doi:10.3762/bjoc. 12.61 